\title{
Changes of Breastfeeding and Of Breast Before and After Surgeries on the Ankyloglossia with Deviation of the Epiglottis and Larynx (ADEL)
}

\author{
Susumu Mukai, Masami Sato, Miwako Nakaji, Kyoko \\ Taguchi, Hinako Taguchi and Yoshiko Fukuchi \\ Mukai Clinic; Yamato, Japan
}

\section{Background}

I read an article recently by L. Dahl in "Clinician's guide to breastfeeding (2015)". In her preface it was written; when breastfeeding doesn't happen easily, it can be due to a simple problem, such as an improper latch or sleepy baby. But often only produce a few ounces of milk... The baby takes leisurely hourlong feeds, then gets hungry an hour later... The baby cries at the breast and becomes frantic... The mother experiences pain every time her baby latches on. Talk to a mother with cracked, bleeding nipples, and watch her cringe at the mere thought of her crying baby 's mouth, and you 'll see how bad it can get.

I discovered these symptoms myself with the birth of my daughter 12 years ago, while I was at my residency. Memories of that time are blurring of exhaustion and frustration. Lucy nursed almost constantly for every for $45 \mathrm{~min}$. My nipples were raw, cracked and very painful, but because my baby seemed healthy, I thought this was normal. Lucy's pediatrician and my own doctor both told me everything was fine and I should just "wait out" the pain-it would stop eventually. She was gaining weight slowly, but within normal parameters.

Over time, the art of breastfeeding was lost. It seems reasonable nowadays to ask your doctor for advice, but what doctor knows anything about the breastfeeding (pp vii-xi) [1,2]. Why has medicine lost proper views on healthy breastfeeding of babies and healthy breasts? Several reasons can be considered.

- Majority of babies (96\%) are ankyloglossia, as seen by the examination of 4-month-old babies described [3].

- Relationship between ankyloglossia and respiration is overlooked [4].

- Symptoms and signs of ADEL are also overlooked [5].

- The need for Paré's frenotomy is denied without correct clinical observation but subjectively [6,7].

- I think that the most important point is that there is no standard for healthy breastfeeding.

\section{Introduction}

Before speak about my research; "Changes of breastfeeding and of breast before and after the surgery of ADEL." It is necessary to

J Nur Healthcare, 2016
*Corresponding author: Susumu Mukai, Mukai Clinic and Mukai Research Institute of Biology, Kanagawa, Japan, E-mail: s-mukai@ da2.so-net.ne.jp

Submitted: 05 Oct 2016; Accepted: 18 Oct 2016; Published: 24 Oct 2016

explain about ADEL and its surgery; the Correction of the Glossolarynx (CGL) and the Expansion of the Vestibular Oris (EVO).

From Renaissance to $20^{\text {th }}$ centuary, frenotomy was performed as important childcares to the new bone babies. The method used was that of Paré's frenotomy. In the $17^{\text {th }}$ century, in Italy almost all babies underwent frenotomy at their baptism whether or not a frenulum was present (Hieronymus, 1537-1619).

The procedure was necessary for breastfeeding and childcare. Technique of Pare is to cut the center of the frenulum and separate the tongue with the finger pressed to the genioglossus muscle. It takes only a few seconds with little loss of blood and is safe.

In addition, immediately after the frenotomy the baby's complexion changes to pink, its voice becomes clearer, the body temperature rises, and the extremities become suppler. A baby with a frown on its face assumes a sunny expression and eye contact becomes possible. Breastfeeding as well as bottle feeding and childcare become easier after Paré's method of frenotomy too.

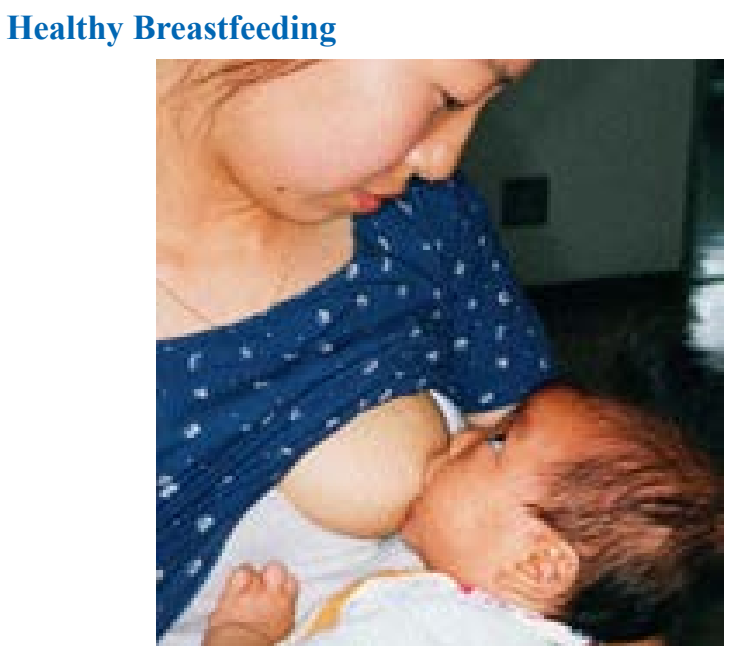

In healthy breastfeeding, the baby opens its eyes wide and latches onto the mother's breast with a wide mouth. It masticates the breast milk when it bites the areola and nipple and gobbles up the milk that gushes out. The movements of the jaws during masticating 
the milk are observable by the movement of both the temporal muscles and the ears.

Ankyloglossia (Figure 1).

\section{Conditions of ankyloglossia}

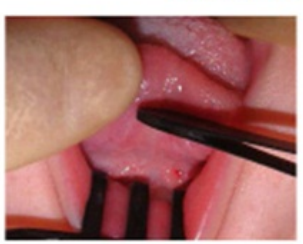

No tongue frenulum

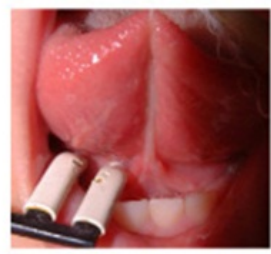

TF started from low er gingiva

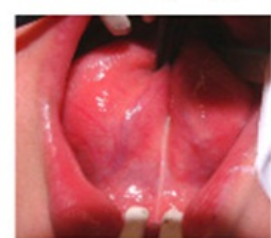

Vestige of tongue frenum(TF)

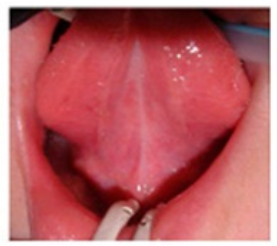

Trace of TF

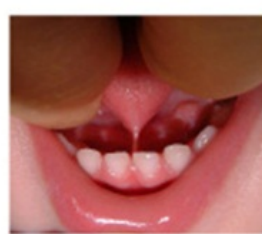

Tongue-tie

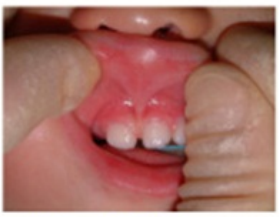

Upper labial frenum
These tongues are those of the ankyloglossia. Generally condition of the ankyloglossia is thought as tongue-tie. (Down right; upper vestibular frenum).

Distribution of the ankyloglossia (Figure 2).

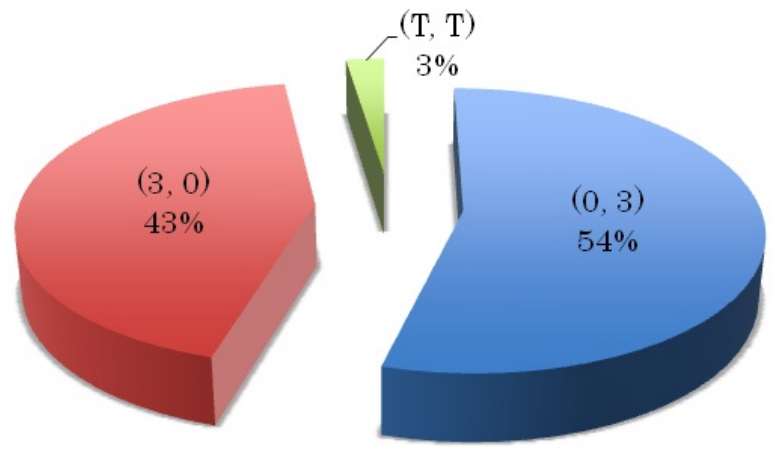

(T,T) Tongue-tie, $(3,0)$ Tongue with frenulum, $(0,3)$ No frenulum). But in reality, as shown in slide, tongue-tie is from 2 to $3 \%$. About $50 \sim 60 \%$ has no lingual frenulum.

$\mathrm{SaO}_{2}$ during sucking (Figure 3).

\section{$\mathrm{SaO}_{2}$ during sucking milk}
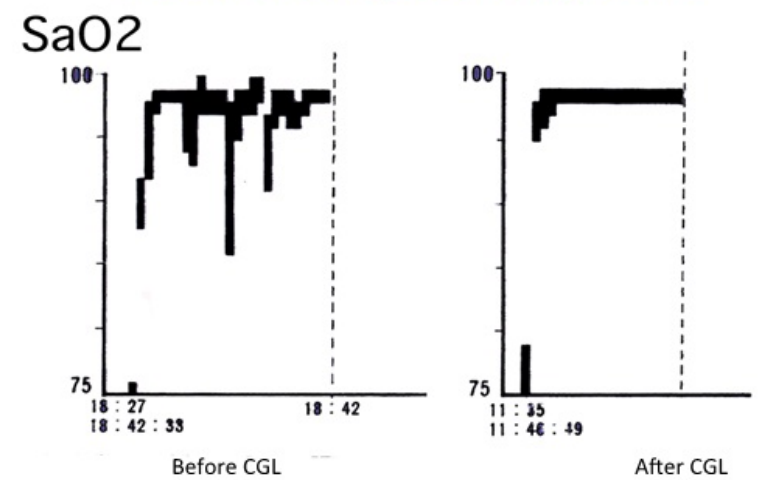

This shows oxygen saturation of a baby during sucking $100 \mathrm{ml}$ of bottle milk. Left is before and right is after CGL. Before operation the baby suffocates frequently and did not finish $100 \mathrm{ml} \mathrm{milk.} \mathrm{But}$ after operation the saturation rate was high and constant. It finished milk in 8 minutes.

Pulse rate during sucking (Figure 4).

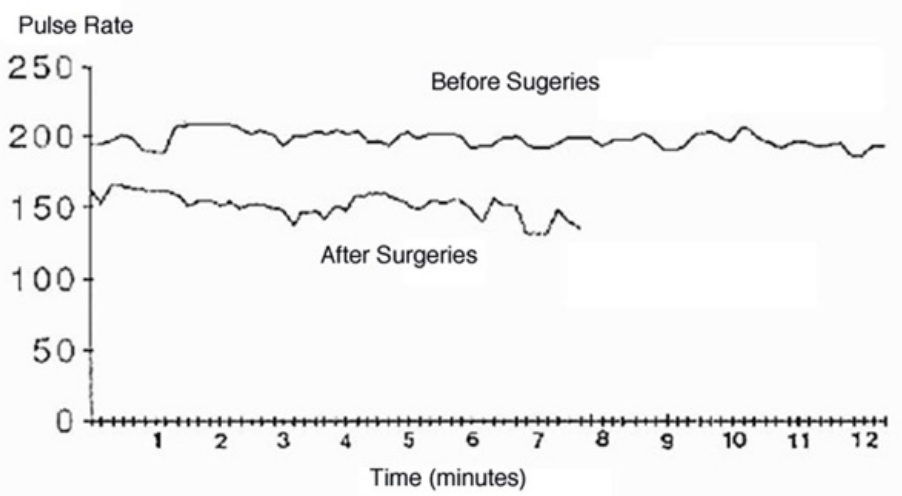

Pulse rate of the same baby before and after during sucking $100 \mathrm{ml}$ milk. Before operation the pulse rate was high and it took more than 12 minutes and could not finish it. After operation it finished milk in 8 minutes with lower pulse rate. These changes suggest that the tongue has a close relationship with the respiratory system.

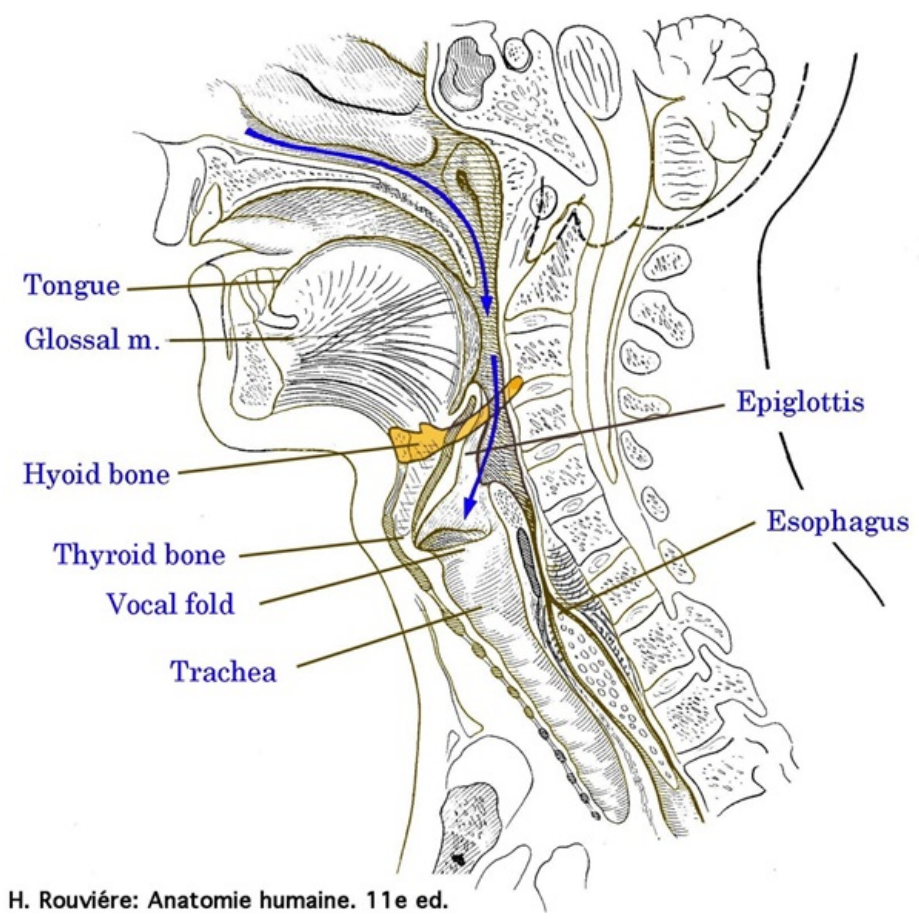

Figure 5 shows upper respiratory anatomy by cross section of the face and neck. The tongue is connected by the hyoid bone and the epiglottis and larynx in the back. Inhaled air by the nose passes the larynx to the trachea and the lung. Foods pass over the larynx to esophagus and the stomach. Routs of respiratory pass and digestive systems cross at the larynx. The first mechanism of the larynx is defense of the trachea and the lung. 
Hyoid bone (red) (Figure 6).

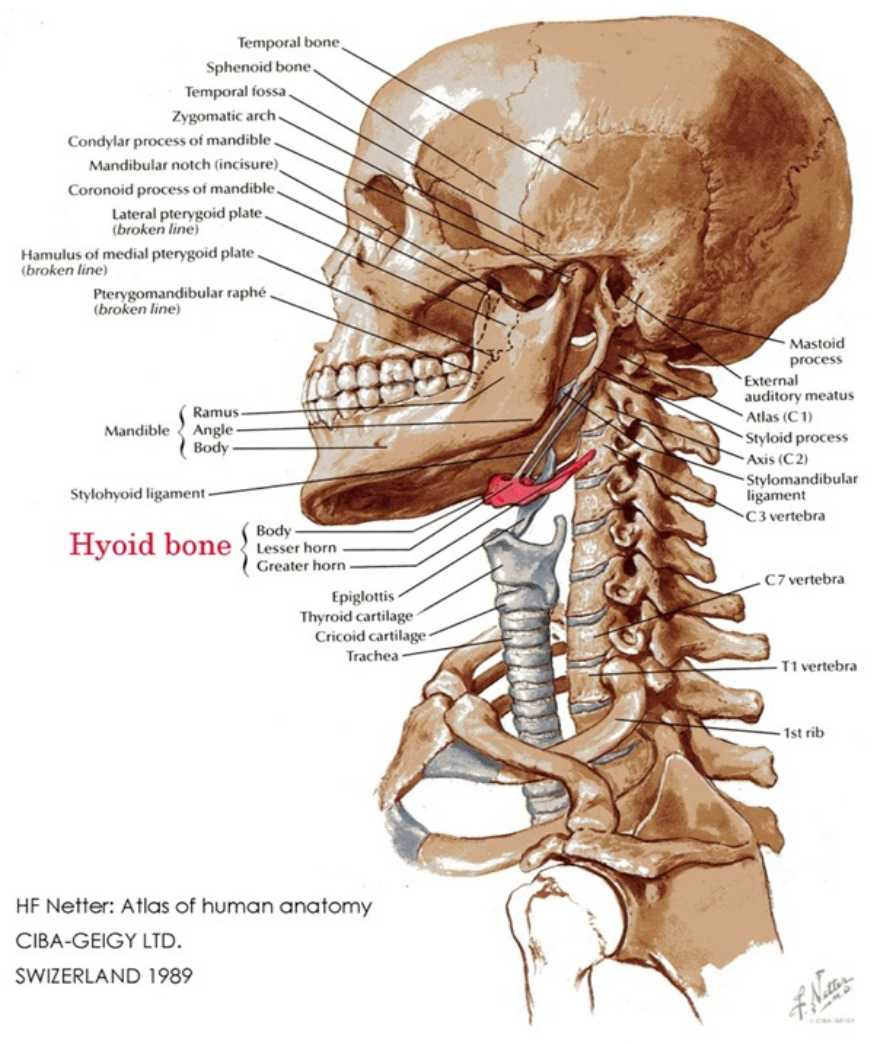

The laryngeal systems are suspended by the hyoid bone. And the hyoid bone (red) is floating in the neck. These situations are anatomically unique to bipedalism.

\section{Normal Larynx (Figure 7).}

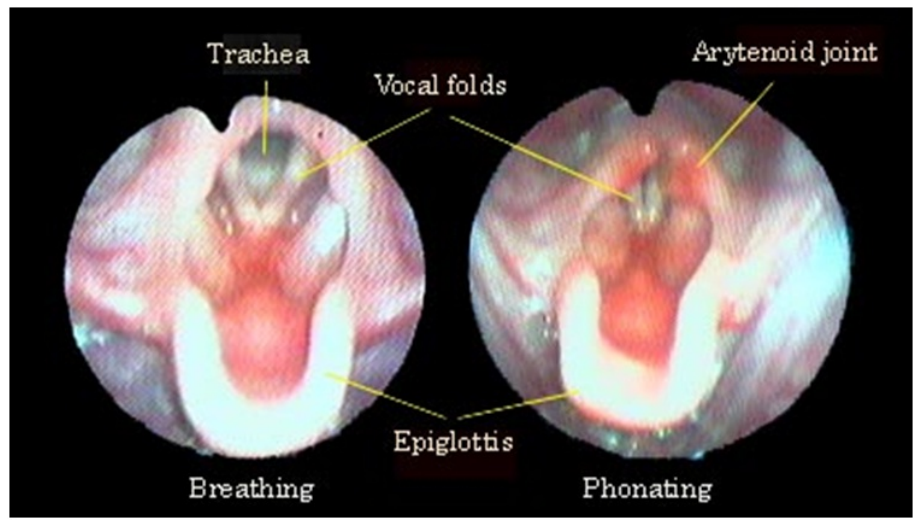

I observed the larynxes of babies with ankyloglossia by laryngeal fiberscope. This is normal larynx observing via nose by laryngofiber scope.

Left larynx is during respiration and right is during phonation. In the left, the epiglottis stands straight towards the choanae. And vocal folds and a part of trachea are observable. The arytenoid joints that open and shut the vocal folds stand straight too. Right; during phonation or making sounds, the epiglottis stands straight towards the choanae and vocal folds are shut and they are observable full length, from ventral to dorsal.

Deviated epiglottis and larynx (Figure 8)

\section{Deviated Epiglottis and Larynx}
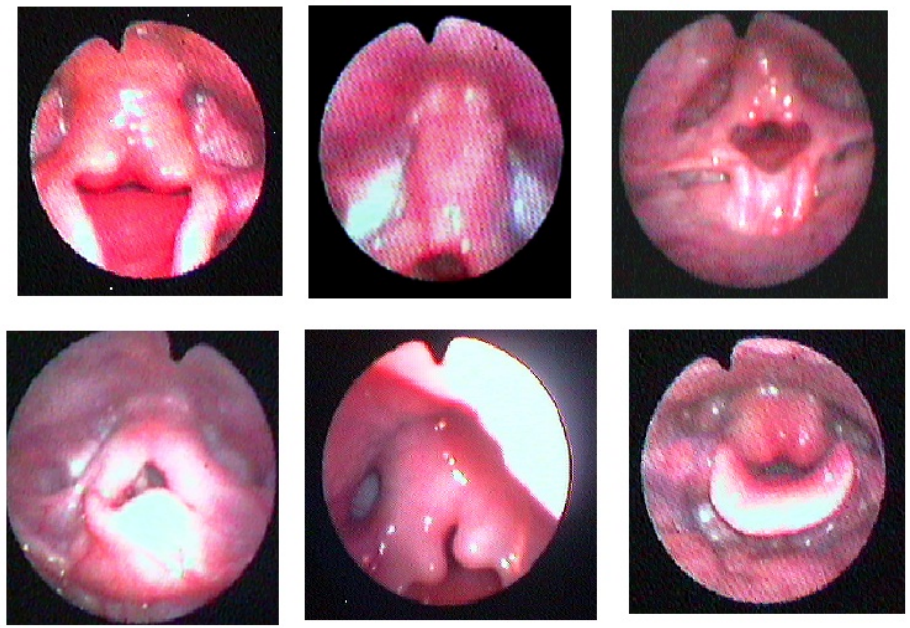

All are deviated larynges during phonations of the babies with ankyloglossia. The observations revealed that these babies had an up and forward deviation of the epiglottis and larynx. Ankyloglossia accompanied deviation of the epiglottis and larynx.

So I renamed this condition as Ankyloglossia with Deviation of the Epiglottis and Larynx (ADEL). To cure these conditions I established two operations. Correction of the Glosso-Larynx (CGL) and Expansion of the Vestibular Oris (EVO). CGL is for tongue, the epiglottis and the development of mandibular bone.

EVO is for nasal respiration and development of the maxillary bone. For maxillary and mandibular bones grow by the influences of both digestive and respiratory systems.

Schematic drawing of ADEL (Figure 9).

\section{Condition of ADEL}

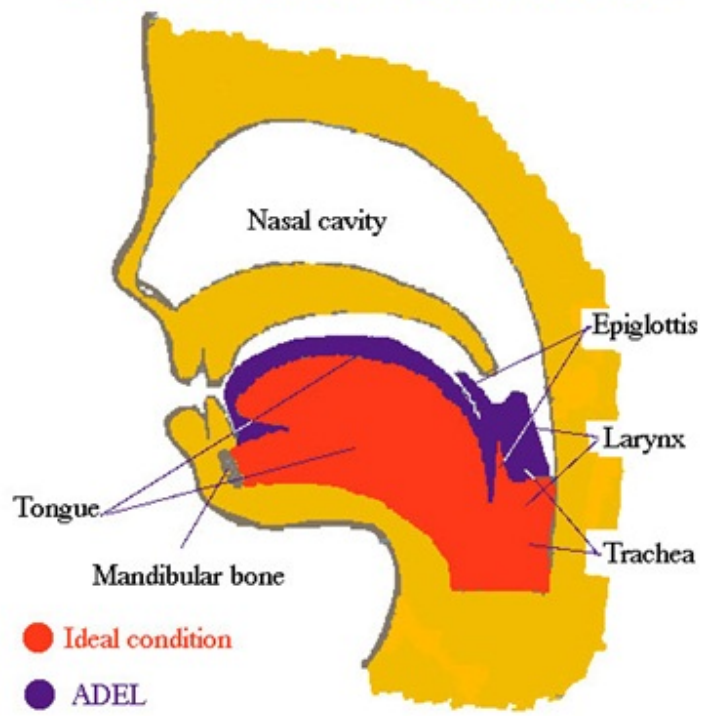


This is schematic drawing of the ADEL. Normal condition is showed red and ADEL is showed blue. In normal condition, when suckling breast, babies stick tongues out and the larynx move upward and it connects with choanae. So they can breath during suckling with easy.

But condition of ADEL, blue, the tongue is up and forward as the results the epiglottis and larynx is up and forward. When the babies with ADEL thrush out their tongues the epiglottis and larynx move up and forwards too.

As the laryngeal position is high, the connection between larynx and choanae is out of alignment. They cannot breath by the nose. So they suffocate during breastfeeding.

Symptoms and signs of babies with ADEL (Figure 10).

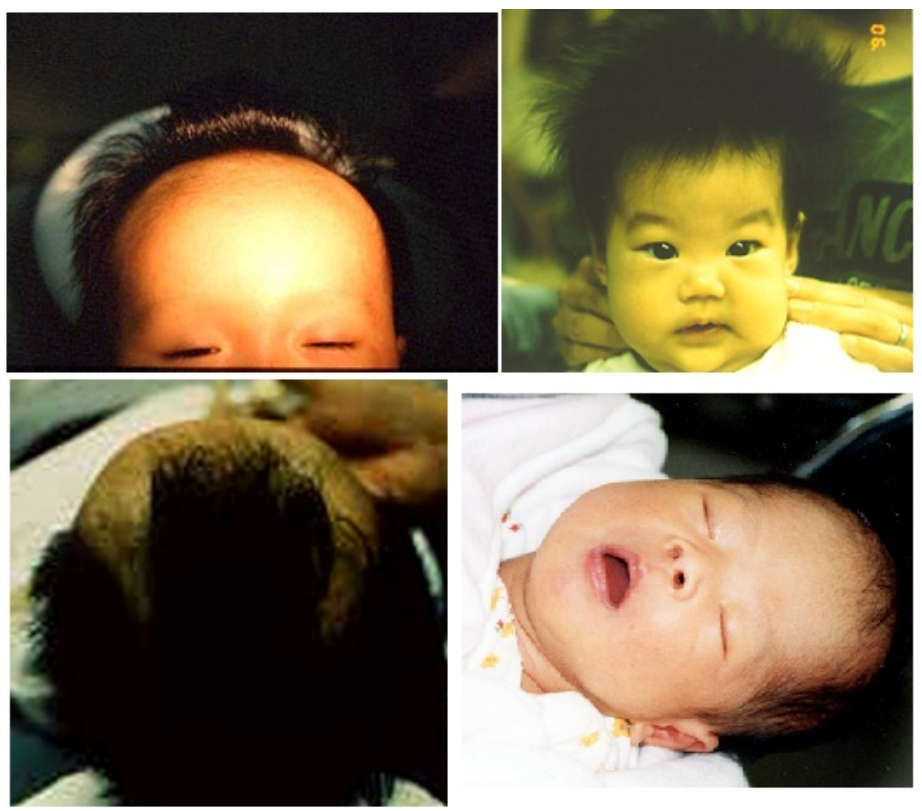

The babies with ADEL presented with a multitude of symptoms and signs both physical and mental. As physical symptoms of the heads we observed, "they are not round," "distorted," "flat at the back." Their hairs are "Easily fall out," "Alopecia," "Piloerection," "Lies flat," and "Scanty."

"Dark forehead," "Dark color around the lips," "Scanty eyebrows and eyelashes," "Frowning expression," "Retraction of orbitotempolar region," "Swelled around the palpebrae," "Hypertrophy of the cheeks." "Difficulty of eye contact."

Their skins are "Cyanotic," "Cutis marmorata," "Pale lips and face,"“Persistent jaundice,"“Eczema," "Rough skin."

Their bodies present "Retracted chest,"“Swelled abdomen and umbilicus," "Swelled and hanged scrotum," "Flatulence," and "Constipation."Extremities present "Weak muscle tone," Bent extremities," "Stiff joints and body," "Weak leap when stand up," "Weak grasping power," "Digit sucking" And "Cold extremities."

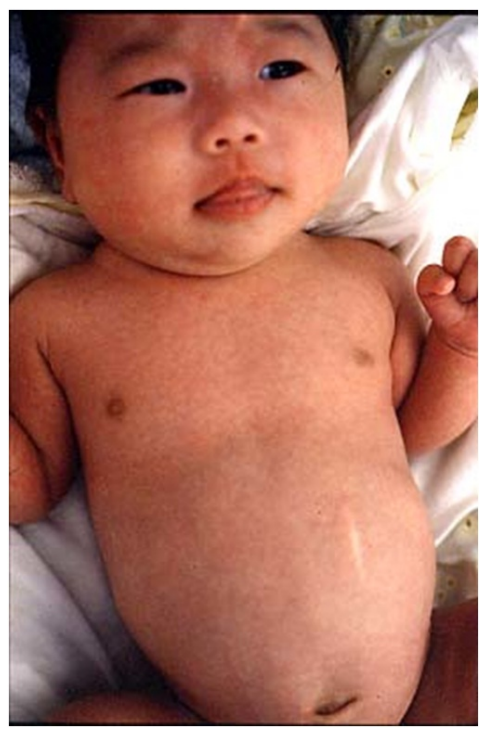

Digit sucking (Figure 12).
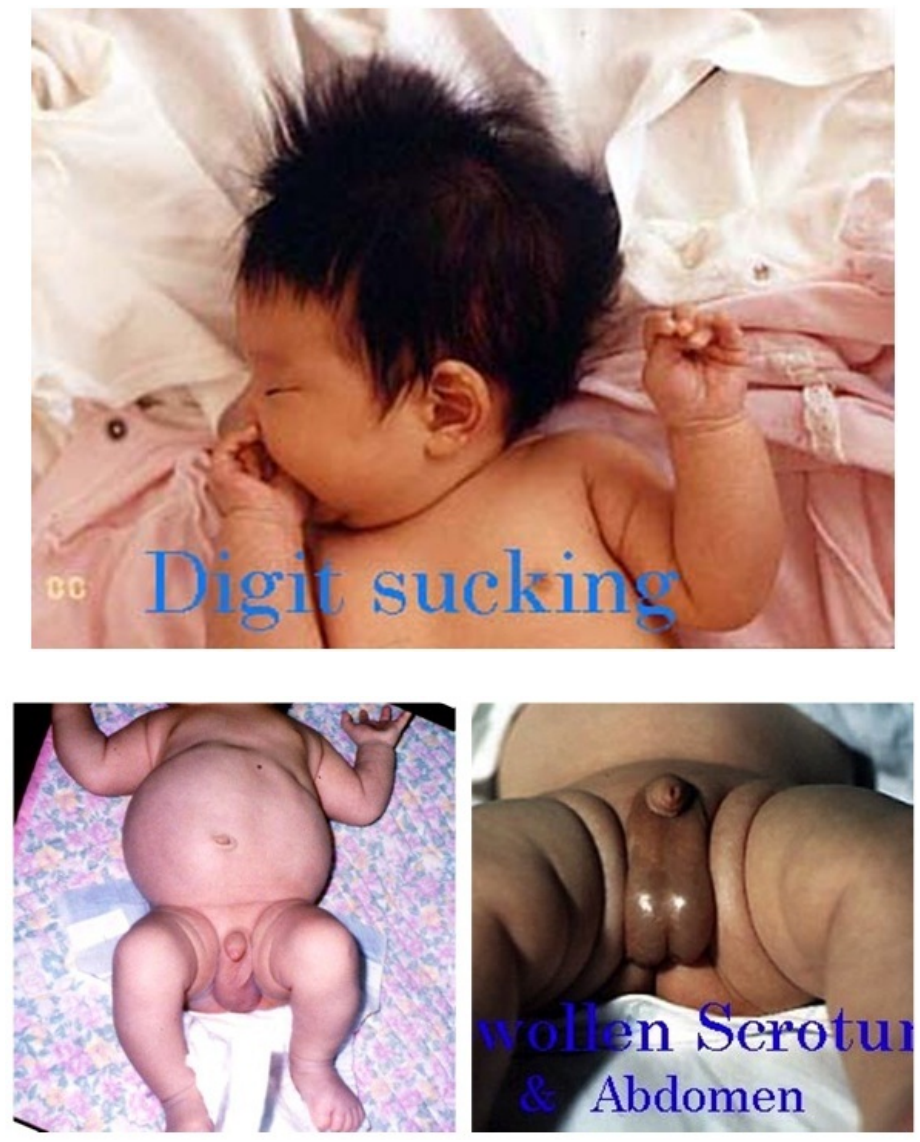

Figure 13: Body; Retracted chest, Swollen abdomen and umbilicus, Swelled and hanged scrotums, Flatulence and constipation.

Drugs for crying (Figure 14).

They cry day and night. Apnea during crying. Crying sounds heard painful, feeble and fierce. Following figures are advertisements of drugs for babies' crying (1 Japan, 2 France). Babies in the world cry hard. (1) Uzukyuumeigan (Japanese) (est.1579 Now).It is written for night crying, diarrhea, Colic cry. 

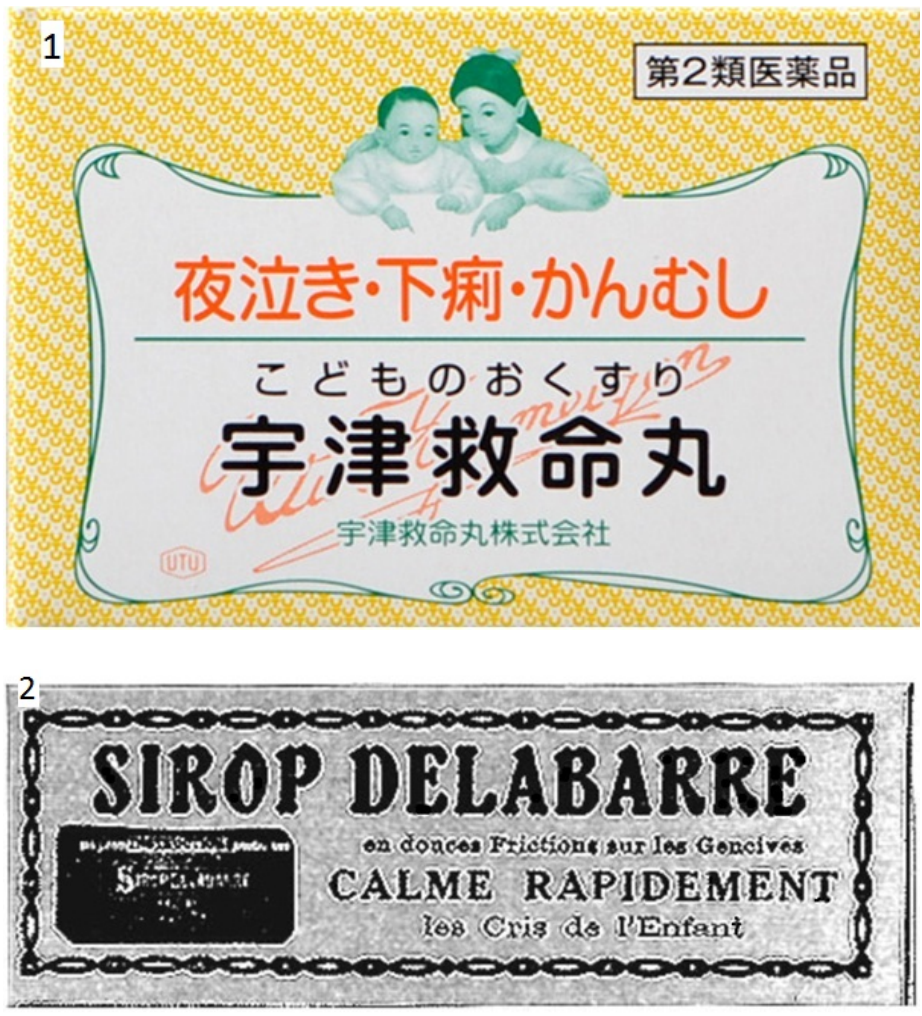

An advertisement for crying in a French Pediatric journal from 1850 to 1973. (Revue Française Pédiatrie (1932/3). Main ingredients are tamarind and safran.

Correction of the Glosso Larynx (CGL) (Figure 15)

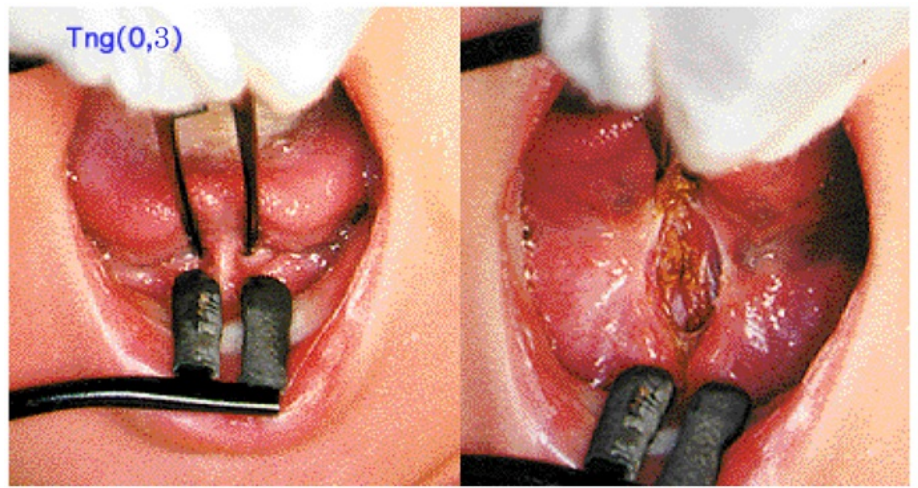

This shows CGL for babies [8]. Holding the center of the tongue and cut the serous membrane and one to two bundles of genioglossus muscles. This procedure takes from two to five seconds without bleeding. Increased of expiratory rate, vital capacity and VC 1.0 (Forced expiratory volume in one second percent) were observed after CGL.

Expansion of the Vestibular Oris (EVO) (Figure 16)

This presents EVO. It cut depressor septi nasi muscle between both canine teeth as high as nasal septum from maxillary bone.

Nasal expansion as well as airflow resistance decreased and the airflow of the nose increased after EVO $[9,10]$.

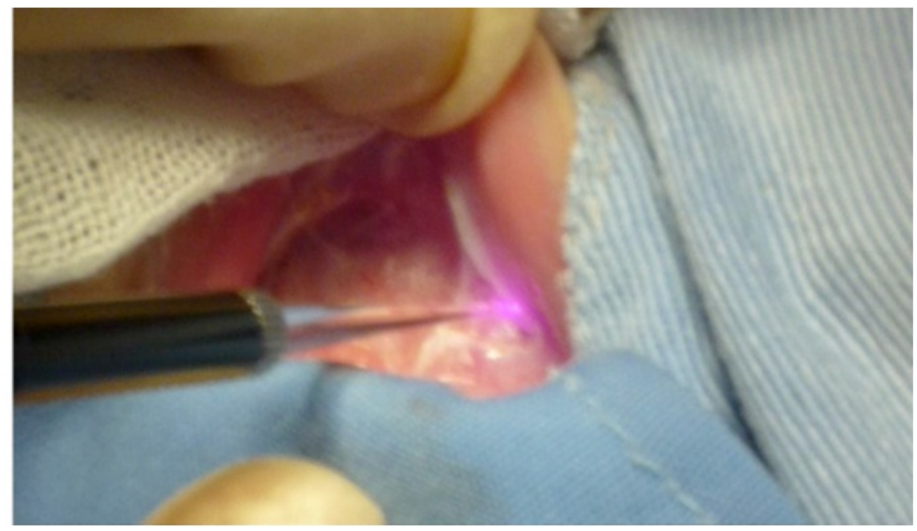

Analysis of sounds of crying, before and after CGL \& EVO (Figure 17).

\section{Changes detected by sound analysis}

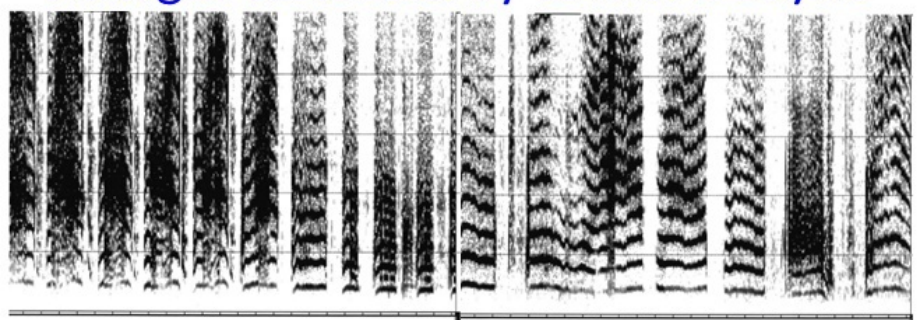

Wh dow

Before CGL \& EVO

After CGL \& EVO

Formants of the sounds are unclear before surgeries. The formants were clearer after surgeries. Crying lengths are longer before than those of after.

Subjective impressions by 8 women who heard 6 cries of babies with ADEL (Figure 18).

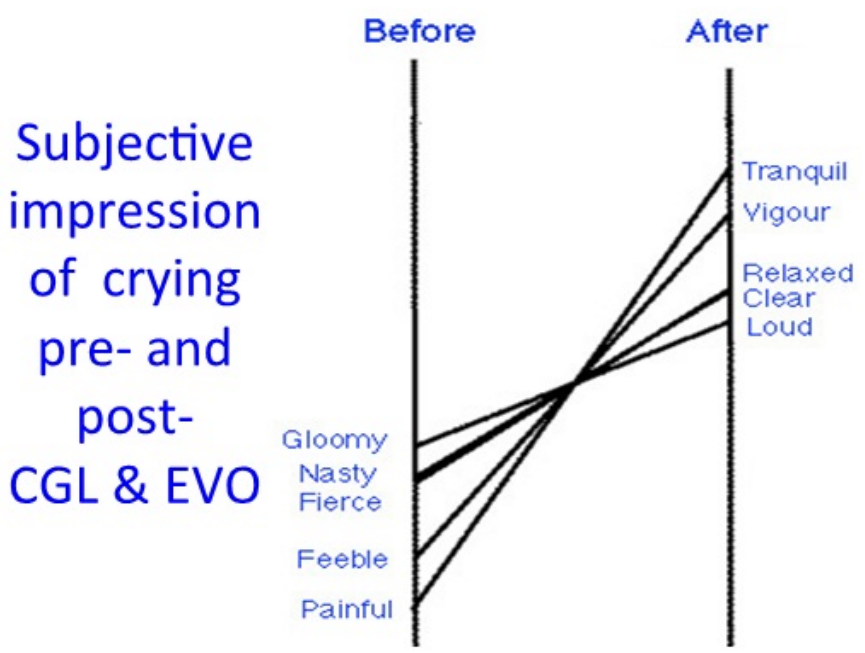

Before surgeries their impressions for cries were gloomy, nasty, fierce, feeble and painful. All their impressions were negative. It 
can be said that negative impressions are a relation to child abuse.

After surgeries there was tranquil, vigor, relaxed, clear and loud. All impressions changed positive.

Changes of 6 weeks boy before and after CGL \& EVO (Figure 19).

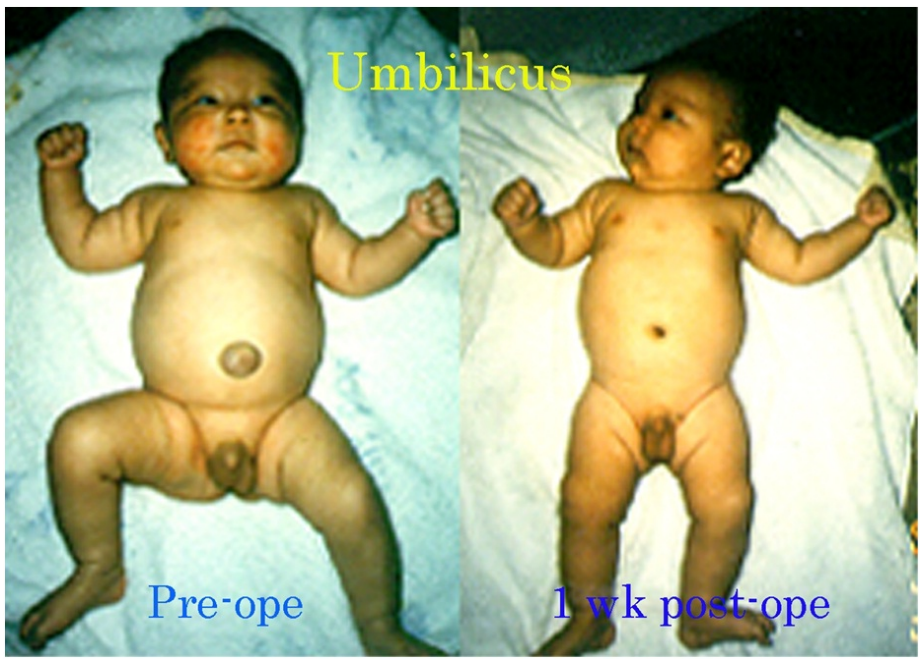

Left presented swelled cheek with eczema. Extremities flexed. Swollen abdomen, umbilicus and scrotum are visible. His joints seem stiff. Right changes all of symptoms mentioned before.

Pathological sucking (Figure 20).
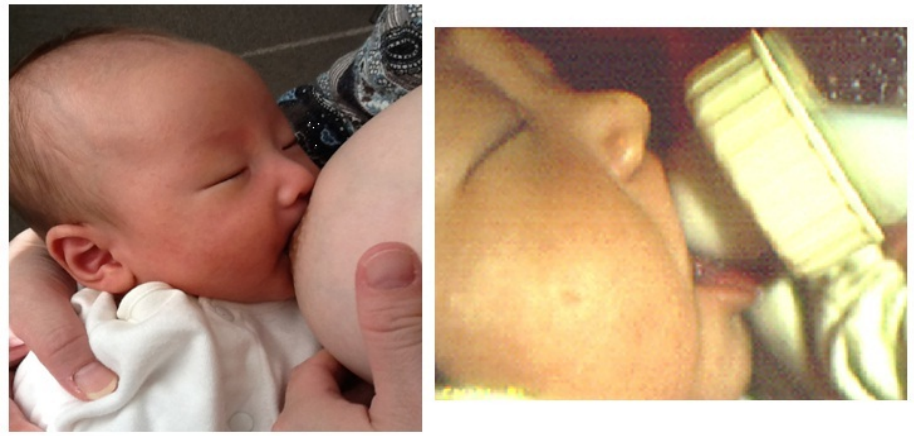

This slide presents pathological suckling, both breast and bottle. They shut their eyes. They only suckle breast or bottle without moving their jaws.

Callous on the upper lip (Figure 21).

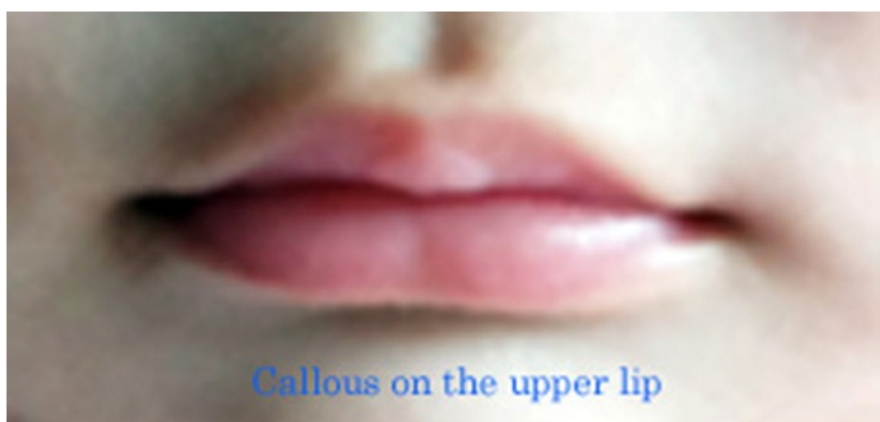

Cornification on the tongue (Figure 22).

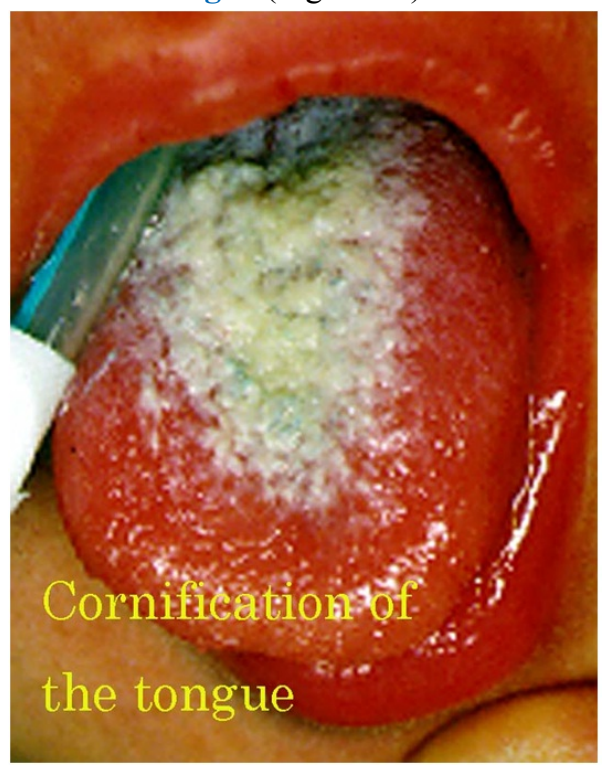

Study

Changes in breastfeeding and in breasts before and after CGL and EVO were studied to 67 babies and their mothers' breasts were studied. Participants of this study were provided information on the procedures and purposes of the study before they were requested to provide written informed consent.

Studied items with regard to babies' breastfeeding

- Whether the baby opens its eyes wide when latching onto the mother's breast. We counted it as negative when the eyes were half closed when suckling.

- Whether the baby latches onto the mother's breast with its mouth wide open.

- Whether a baby has a callus on its upper lip. Babies with ADEL have a short upper labial frenulum as well. The upper frenulum attaches to the upper labium and gingiva. The condition results in a narrow upper oral vestibulum. When a baby latches onto the mother's breasts its upper lip turns inside and rubs against the skin of the mother's breast. As a result a relatively long and wide callus forms on the center of the upper lip.

- Whether the baby moves its jaws during breastfeeding. When a baby latches onto the breast the nipple is pushed into the sucking sulcus of the hard palate by the infant's tongue. Then the baby masticates the breast rhythmically with its jaws. Movements of both the temporal muscles and ears are visible when a baby masticates breast milk. When both movements were observed we counted it as positive. No movement and/or one movement were counted as negative.

- Whether the baby has a white dorsum tongue by cornification. Incorrect movements of the tongue during breastfeeding result in white cornification on the dorsum tongue. It causes pain and/or injuries to the mother's nipples.

- Whether the baby makes sounds like "tsukon-tsukon" or "chupa-chupa", during breastfeeding. ("Tsukon-tsukon" or "chupa-chupa" is an onomatopoeia in Japanese. These are the 
suckling sounds that are heard as not soft but rather as hard clicking sounds.)

\section{Results}

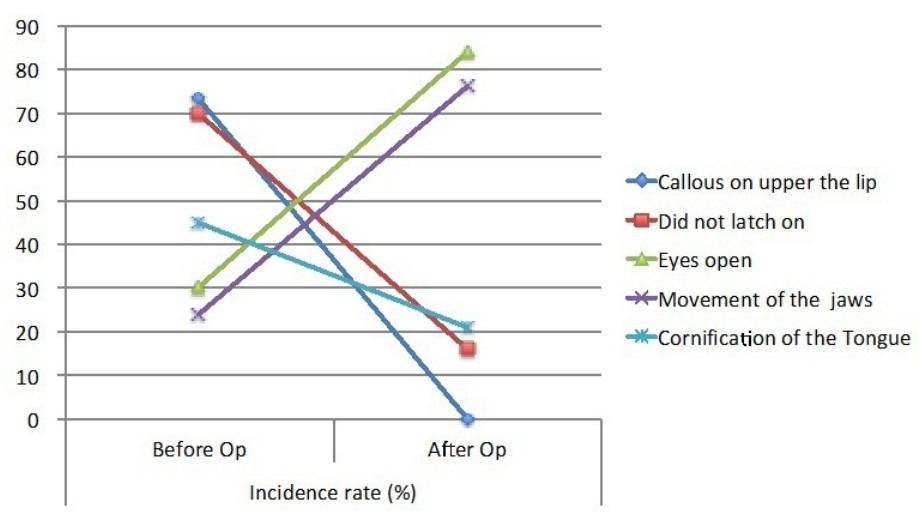

Figure 23: Changes in babies' symptoms pre and post operations.

As to changes in symptoms of babies with ADEL, callouses on the upper lips, not latching onto the breasts, and cornification of the tongue decreased and opening of the eyes and movement of the jaws increased 1 month after CGL and EVO.

\section{Changes in the breasts after babies' surgeries}

Healthy breasts of breastfeeding mothers are soft and appear healthy with no palpable masses within. The shapes of nipples, areola, and breasts are normal. The following conditions were examined before and after the babies' surgeries.

Pathological breastfeeding affects both the mother's nipples and breasts.

- Nipple pain.

- Flattening of nipples.

- White debris or cheese formation on top of nipples.

- $\quad$ Presence of blisters on nipples.

- Cracked nipples.

- $\quad$ Soft, swollen or shrunken breasts.

- $\quad$ Pain after breastfeeding.

- Presence of mastitis.

- Presence of palpable masses.

- If present, distribution of masses in the breasts

Pathological Nipples (Figure 24).

Erosion of the nipple

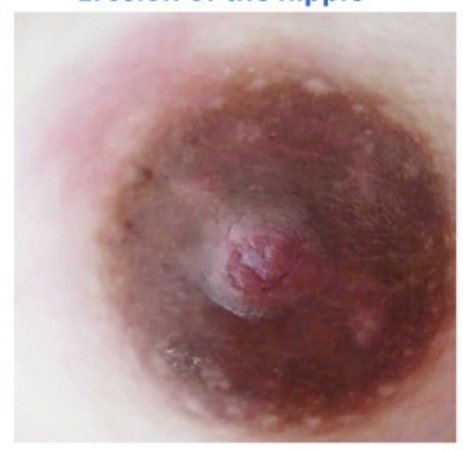

White debris and flattening

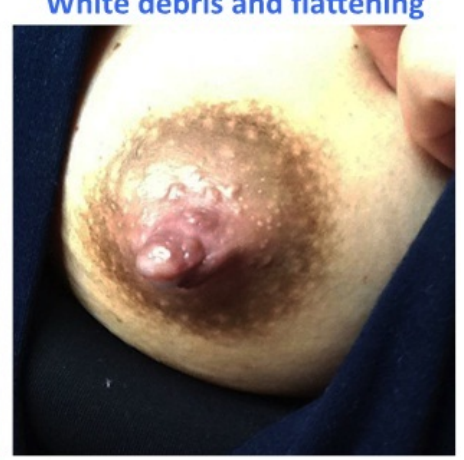

Breast pain (Cracked nipple) and Swelled breast (Figure 25).

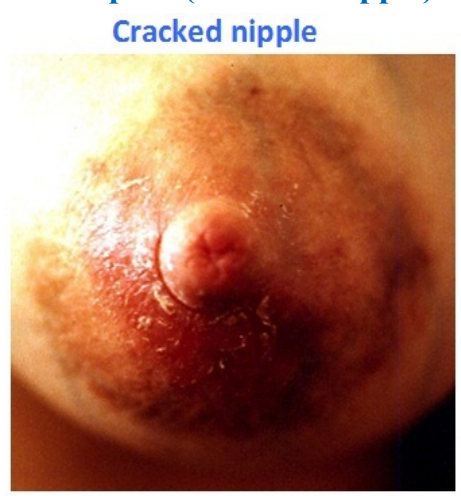

Swollen breast (masses)

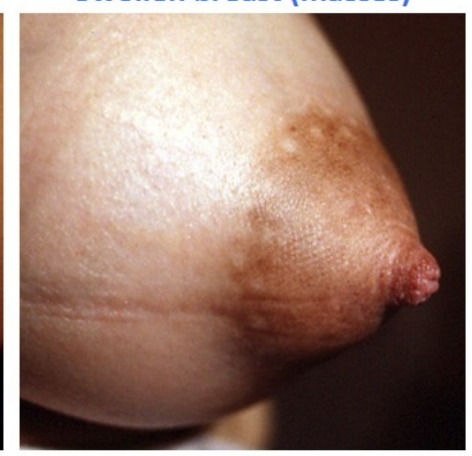

Shrunken breast \& Healthy breast (Figure 26).

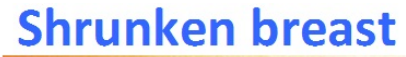

\section{Healthy breast}
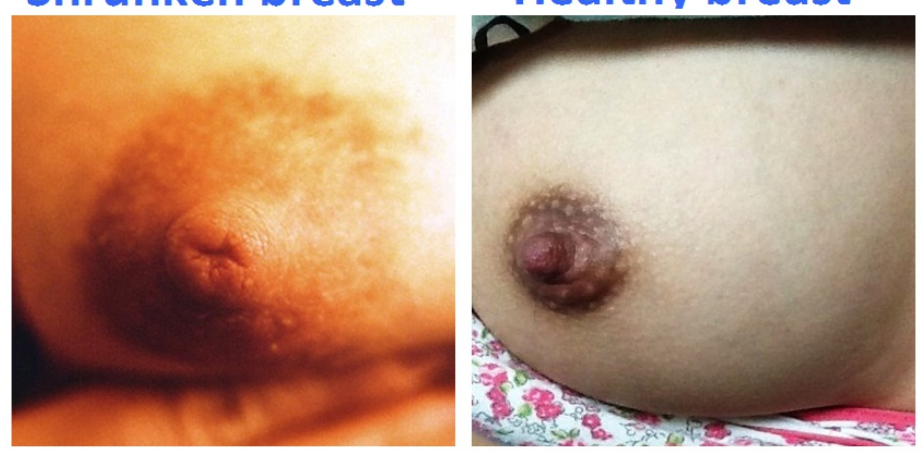

Shrunken breast means there were no suckling stimulations by the baby. On the right is a healthy breast. Its milk is serous and sweet.

Presence of palpable masses (Figure 27).
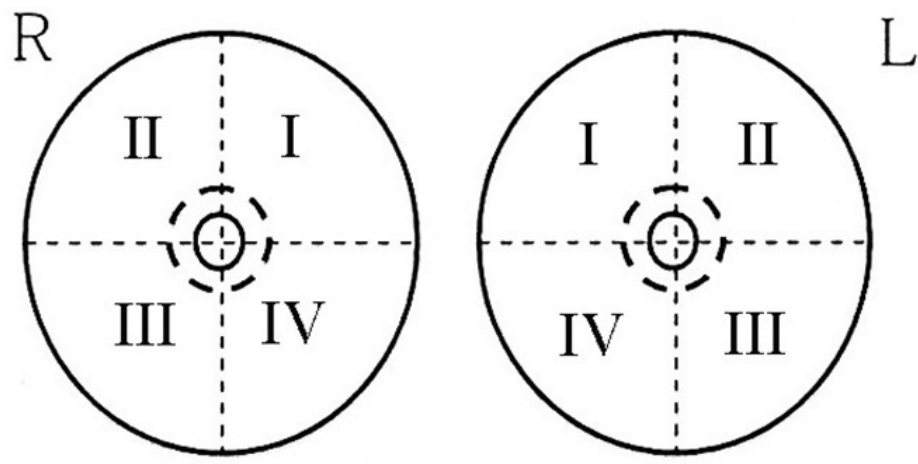

A breast was supposed as a circle, a Cartesian coordinate was made at the center of a nipple, and the breast was divided into four quadrants.

The right breast was divided into four quadrants counter-clockwise from the upper-ventral I quadrant to II, III and IV quadrants (Figure $27 \mathrm{R})$. The left breast was divided the same way clockwise from the left upper-ventral I quadrant to the bottom ventral IV quadrant (Figure 27 L).

Distribution of masses in right and left breasts

Red circles include findings before the babies' surgery and blue 
circles show findings after the surgeries. Right breast had 105 masses before babies' surgery but only 10 masses after. The left breast had 80 before and 30 after.
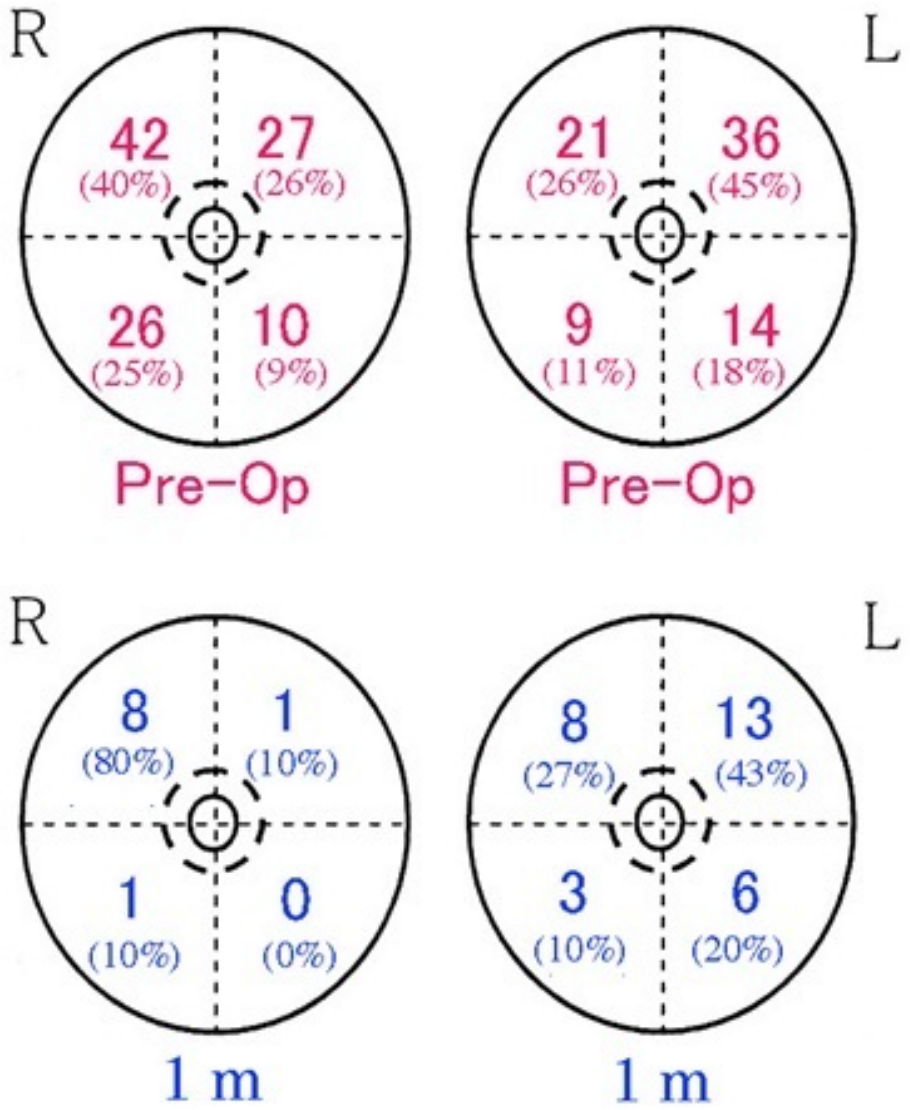

Before surgeries the presentation rates of masses in the left and right quadrants were almost the same.

Cure rate for the right breast was higher than for the left. Participants of this study were provided information on the procedures and purposes of the study before they were requested to provide written informed consent.

Changes of the breasts (Figure 29).

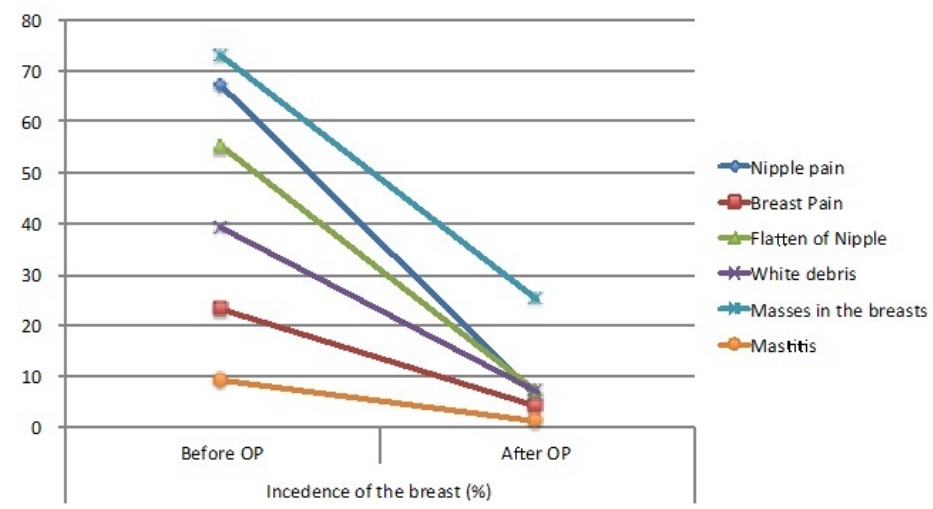

Pathological breasts by babies with ADEL cease one month after CGL and EVO of babies.
Summary

Babies that are born with ADEL cannot breastfeed correctly and hurt their mothers' breasts. ADEL hinders not only the normal development of upper and lower jaw bones, nose, and occlusions, but also prevents mothers from breastfeeding. It prevents communication between mother and child as well as others.

Remarkable ameliorations of these reported cases, both of babies and mothers, revealed that surgical interventions are necessary for babies with ADEL. In addition, it proved that aid in breastfeeding by midwives is invaluable for mothers.

\section{References}

1. Linda Dahl (2015) Clinician's guide to breastfeeding. Springer International Publishing Switzerland.

2. Suzuki H, Nakaji M, Mukai S (1993) Relationship between babies with ankyloglossia and disturbance of their mother's breast (In Japanese). Annals of Ankyloglossia with Deviation of the Epiglottis and Larynx 3: 74-84.

3. Mukai S, Mukai C, Asaoka K, Nagasugi S, Yoshimi Y (1993b) Distribution on conditions of tongue, hair and skin in babies with four month old (Japanese with English abstract). Zetuyuchakushou Kennkyuukai Kaihou Annals ADEL 3: $1-12$.

4. Mukai S, Mukai C, Asaoka K (1993) Congenital ankyloglossia with deviation of the epiglottis and larynx: symptoms and respiratory function in adults. Ann Otol Rhinol Laryngol 102: 620-624.

5. Butlin H, Spencer W (1900) Congenital ankyloglossia, adherent tongue, or tongue-tie. In Disease of the tongue (Butlin A edn). Cassel Co Ltd 30-37.

6. Cullun IM (1959) An old wives tale. Br Med J 2: 497-498.

7. Spencer W, Cade S (1931) Tongue-tie; Ankyloglossia. In Disease of the tongue. K. Lewis \& Co. Ltd. 18-20.

8. Mukai S (1994) Changes after correction of the glosso-larynx (CGL); from patients' reports that received CGL (In Japanese). Zetuyuchakusho Kenkyukai Kaiho (Annals ADEL)4, 1-156.

9. Mukai S (2013): Dilatation of the nasal valve by expansion of the vestibular oris (EVO) Health 5: 21-25.

10. Nitta M, Mukai S (2004) Height of the Nose, Ala Nasi and Lip Increase in Size by Expansion of the Vestibular Oris (in Japanese). Zetuyuchakushou Kenkyuukai Kaiho (Annals ADEL) 12: 10-14.

Copyright: (2016 Mukai S, et al. This is an open-access article distributed under the terms of the Creative Commons Attribution License, which permits unrestricted use, distribution, and reproduction in any medium, provided the original author and source are credited. 